\title{
Global Non-State Actors (2018)
}

\author{
Karen Da Costa*
}

In relation to global actors, 2018 has been a remarkable year. A noteworthy development is the adoption of a new edition of the Sphere Handbook, ${ }^{1}$ marking the 2oth year anniversary of the Sphere movement, which comprises a community of practice among humanitarian workers across the globe. The Sphere Handbook identifies a set of common principles and universal minimum standards to be applied in humanitarian operations, including in disasters. Key novelties of the 2018 edition are the emphasis on the role of local authorities and communities, as well as the need for context analysis when applying the standards. Furthermore, new provisions have been incorporated, for example regarding WASH, healthcare including palliative healthcare, security of tenure in shelter and settlement, and well as references to cash-based assistance programs, and relief operations in densely populated areas.

Another noteworthy publication issued in 2018 is The State of the Humanitarian System (sOHs) report, ${ }^{2}$ authored by ALNAP (Active Learning Network for Accountability and Performance), a global network of key actors in the humanitarian sector, including NGOs, UN agencies, members of the Red Cross/ Crescent Movement, donors, academics and consultants. The report covers the period between January 2015 and December 2017 and assesses the overall performance in the sector. Disasters associated with natural hazards are among the situations covered in the report.

The year of 2018 has also been important for the International Federation of Red Cross and Red Crescent Societies (IFRC), notably through its Disaster Law Programme (DLP), together with Red Cross/Red Crescent National Societies involved with the development of disaster law. Many positive developments reflect the IFRC DLP policy advocacy efforts, together with the work of National Societies in this regard.

* Senior Lecturer, University of Gothenburg.

1 For the full edition of the 2018 Sphere Handbook, see <https://spherestandards.org/hande book-2018/>, last accessed (as any subsequent URL) on 26 June 2019. Note that the 2018 Sphere Handbook will also be covered in Dug Cubie, 'Humanitarian Assistance and International Law', in this issue.

2 For the full report see <https://sohs.alnap.org/system/files/content/resource/files/main/ SOHS\%20Online\%2oBook\%201\%2oupdated.pdf >. 
In terms of laws or regulations adopted in 2018, few countries adopted new law and policy instruments drawing on recommendations of RC/RC National Societies and IFRC. They are: Costa Rica, El Salvador, Guatemala, Honduras, Indonesia, Nicaragua, Panama and Samoa. From these, the six Central American countries revised their CATAI/CCAH ${ }^{3}$ Manuals to incorporate the Central American Protocol to facilitate the shipment, transit and receipt of humanitarian aid within the Central America Integration System (SICA). This development aims to improve, harmonize and simplify the transit of humanitarian relief items after disasters, across Central America.

In Samoa, the National Disaster Management Plan (NDMP) was endorsed in January 2018. ${ }^{4}$ This document was strongly influenced by the Samoa Red Cross and IFRC. The result of this advocacy work is that many important provisions were included or strengthened, such as on the auxiliary role of the RC National Society, 5 together with provisions on international assistance and on genderbased violence in disasters.

In relation to international assistance, Samoa's National Disaster Management Plan (NDMP) indicates that the National Disaster Council is the body in charge of requesting international assistance to aid agencies and donors, when it 'has become clear that the situation at hand is beyond the capabilities of the existing national resources'. ${ }^{6}$ The Plan also points out to a Standard Operating Procedure to be followed, including a request form to be filled in cases of request of international assistance. ${ }^{7}$ According to the Plan, the coordination of the distribution of aid to communities is done by the Disaster Advisory Committee, taken into account needs assessments. In relation to clearance of international aid, there is a provision aiming to facilitate the necessary arrangements for disaster relief items, in relation to Customs and Agriculture \&

3 CATAI refers to 'Technical Advisory Committee for International Humanitarian Assistance'. CCAH stands for 'Centre for the Coordination of Humanitarian Assistance'.

4 See <https://reliefweb.int/report/samoa/government-launches-its-national-disaster-mans agement-ndmp-and-national-action-plan-nap $>$, and $<$ https://www.mnre.gov.ws/government -launches-its-national-disaster-management-ndmp-and-national-action-plan-nap/>.

5 For example, the National Disaster Response Framework for Samoa contains among its Guiding Principles the provision according to which 'Risk reduction, disaster preparedness, response and recovery are the responsibility of all national actors'. The principle is further explained with the indication that, at the national level the ministries are the lead agencies 'which includes among others, the Samoa Red Cross, non-governmental organizations, private sector, communities and donors'. See Section 1.3. (in file with the author).

6 National Disaster Response Framework for Samoa, Section 3.3., especially 3.3.1. (in file with the author).

7 Ibid., Section 3.3., and Appendix 7 (in file with the author). 
Fisheries. There is also a provision indicating that 'goods purchased locally with disaster relief funding are to be exempt of duty'.

Additionally, the Samoan Plan includes provisions on the need for strengthening the mainstreaming of disaster risk reduction across sectors, including by systematically integrating commitments in relation to gender equality, disability issues, and human rights in general. ${ }^{9}$ There are few references to gender based violence (GBV) in the Plan, notably the monitoring and reporting of G BV are mentioned among the activities aimed at in the disaster response phase, which are linked to the protection of life, security and physical integrity. Again, the Plan lists among the functions of the health sector to estimate costs for the health management of GBV and violence against women, in the preparedness phase of disasters. ${ }^{10}$

Similarly, the National Disaster Response Framework for Indonesia was approved by the Government of Indonesia in March 2018. The National Disaster Response Framework (NDRF) is Indonesia's primary response document and aims to clarify roles, responsibilities, and the organisation of response to a disaster. It includes specific roles for the Indonesia Red Cross (PMI) and IFRC as national/international partners to the government in a number of areas. Overall, it is a forward-looking framework, which includes provisions on genderbased violence in disasters as well as displacement / protection issues, and which underscores the importance of integrating cross-cutting issues such as gender equality, the environment and human rights across disaster response. The NDRF aims to ensure that no segment of Indonesian society is excluded or marginalized during disaster events or disaster response activities. ${ }^{11}$ Both the Indonesia Red Cross Society and IF RC have been active in their contribution to the NDRF for the past couple of years and have positively influenced the framework.

Additionally, throughout $2018 \mathrm{RC} / \mathrm{RC}$ National Societies and IFRC have been involved in the legal drafting procedures of disaster law related issues in further 17 countries. They are: Bhutan, Costa Rica, Dominica, Fiji, Lao, Malawi, Mongolia, Nepal, Panama, Peru, South Sudan, Sudan, Tokelau, Tonga, Tuvalu, Uganda and Vanuatu. The adoption of such procedures is expected to take place in 2019-2020.

Also, in 2018 national laws and policies in various countries better defined the auxiliary roles of RC/RC National Societies, often through inclusion of

$8 \quad$ Ibid., Section 3.3., especially 3.3.2. (in file with the author).

$9 \quad$ Ibid., Sections 2.2. and 2.3. (in file with the author).

$10 \quad$ Ibid., Section 5.2.8. (in file with the author).

11 See Indonesia National Disaster Response Framework (NDRF), March 2018, 3 (in file with the author). 
express provisions of the role of the $\mathrm{RC} / \mathrm{RC}$ National Society in $\mathrm{DM}$ processes and activities. As a general rule, these developments were due to RC/RC National Societies' engagement and contribution to the drafting processes of policies or bills developed by national governments. Furthermore, comments provided by RC/RC National Societies were largely incorporated in such regulatory instruments, most notably recognizing the role that the $\mathrm{RC} / \mathrm{RC}$ National Society has to offer in national disaster management. Such legal and policy developments were adopted by the following countries: Argentina, Bhutan, Costa Rica, Indonesia, Kiribati, Lao, Mongolia, Nepal, Samoa, Tonga and Vanuatu.

In terms of Global tools covering disaster law, IFRC's DLP has undertaken the development of a new tool, the 'Global Disaster Risk Management Law Index' (the Index) with the pro bono support of White \& Case law firms. The Index will provide guidance as to the current DRM systems in each country, with a focus on the entire DRM spectrum - ranging from risk reduction, to preparedness, response and recovery. By using this tool, countries around the world will be able to identify specific areas that could be strengthened in their national DRM law and policy, according to the indicators developed for this project and in line with global best practice.

Another relevant development regards IF RC's Disaster Law Programme ongoing research in preparation for the development of a new 'Checklist on Law and Disaster Preparedness and Response', that will update the 2015 version, currently used. ${ }^{12}$ The checklist provides a list of questions aiming to assist lawmakers, officials, and related actors in identifying how existing laws may provide the best support for disaster risk reduction. The checklist encompasses not only disaster risk management, but also other relevant sectoral laws and regulations, such as those covering the environment, land and natural resource management.

Furthermore, in terms of research that inform legislative advocacy, the IFRC and National Societies completed in 2018 various country case studies (Belize, Dominica, Honduras, El Salvador, Samoa, Sudan, Timor Leste, Vanuatu, notably the Legal Mapping on DRR and CCA in Central America and Disaster Displacement Research in Asia Pacific).

Research in Nepal on Law, Gender Equality, and Protection from SGBV (sexual and gender-based violence) in Disasters was completed in 2017 and it was launched by the Minister of Women, Children and Senior Citizen Affairs in

12 For the current "Checklist on Law and Disaster Preparedness and Response", see $<\mathrm{https} / /$ www.ifrc.org/Global/Publications/IDRL/Publications/The\%2oChecklist\%2oon\%20 law\%2oand\%2oDRR\%2oOct2015\%2oEN\%2ov4.pdf>. 
Nepal on 22 March 2018. ${ }^{13}$ During the launch, an official commitment was made by the government, to implement recommendations into relevant legal and policy frameworks. ${ }^{14}$ The report is part of IFRC's global research on Law, Gender Equality and SG BV in Disasters.

In terms of intergovernmental advocacy, IFRC's DLP hosted a side event at the Afro-Arab DRR platform in October 2018. The side event 'Law and DRR', focused on the impact developing climate-smart DRR laws and policies can have on improving the preparedness and climate change adaptation capacity of communities. During the platform IFRC was able to promote its key messages by influencing six clauses of the Tunis Declaration on accelerating the implementation of the Sendai Framework for Disaster Risk Reduction ${ }^{15}$ as well as the Joint Communiqué. ${ }^{16}$ IFRC's DLP was also represented as a panelist in the Plenary Working Session 2: Stepping up efforts towards achieving target (e) of the Sendai Framework by 2020. Furthermore, the DLP jointly with the African Union Commission organised a side event on the Impact of Law in Disaster Risk Reduction.

Finally, IFRC took part in the Pacific Island Forum Secretariat Consultation on the Boe Declaration from 26-27 November 2018, in Fiji. ${ }^{17}$ The Boe Declaration is a Pacific regional security declaration setting out the commitment of the Pacific Leaders to good governance, liberty of the individual under the law, upholding democratic processes and recognising the vulnerability of member countries to threats to their security. The expanded concept of security under the Boe Declaration recognises Disaster Risk Management and Climate Change as a security threat. One of the key initiatives arising out of the consultations was to carry out a law mapping in the Pacific. In the Disaster Risk Management space there was strong support for the DRM Laws to be mapped against the IDRL guidelines, through collaboration between PIFS (Pacific Islands Forum Secretariat), SPC (Secretariat of the Pacific Community) and IFRC.

13 For the full report in English, see $<$ https://redcross.eu/uploads/files/Positions/Humanir tarian\%2oaid/SGBV\%2oin\%2odisasters/Gender\%2oSGBV\%2oReport_\%2oNepal\%20 HR.pdf $>$.

14 Regarding the official launching of the report, see $<$ https://media.ifrc.org/ifrc/2018/07/10/ launch-nepal-case-study-effective-law-policy-gender-equality-protection-sgbv -disasters/>.

15 For the Declaration, see <https://www.preventionweb.net/files/57759_finaladopted drafttunisdeclarationı.pdf $>$.

16 For the Joint Communiqué, see <https://www.preventionweb.net/files/57759_commu niqueofthechair.pdf>.

17 See $<$ https://www.forumsec.org/boe-declaration-on-regional-security $>$. 
Additionally, in 2018 over 25 inter-governmental, inter-agency and academic fora actively engaged on legislative advocacy issues relating to disasters, many of them thanks to the work of the IF RC and of National Societies. This includes two regional conferences on 'Legislating for Climate Smart Disaster Risk Management' in the Pacific and in Latin America respectively.

With regards to knowledge production, the IFRC, jointly with the School of Law of University College Cork of Ireland, launched a new research project named 'Linking natural hazard vulnerabilities and poor sustainable development outcomes - a comprehensive analysis of disaster risk management frameworks and practices in Africa and their impact on the realization of sustainable development'. This is a 3-year partnership for the development of a comprehensive analysis of the DRR framework in Sub-Saharan Africa. Following a baseline survey done in approximately 15 countries, the study will also feature data collected through key informant interviews as well as in-depth case studies on South Africa, Kenya, Sierra Leone and Mauritius.

In relation to further actions, this time taken by national authorities, that have an impact on global actors working in Disaster management, it is worth citing regulations adopted by the Government of Indonesia, after the earthquake and tsunami that hit the Central Sulawesi Province in 2018. ${ }^{18}$ The regulations were aimed at international NGOs seeking to provide assistance, and basically indicated a set of measures to be taken by potential international actors in order to be able to conduct their activities. They included the compulsory registration of INGOs' activities and registration of their foreign personnel before the National Disaster Management Body, as well as the need for conducting activities with local partners. Although attracting some criticism, the measures were perceived by others as necessary for avoiding chaos at the disaster scene and also to make sure that disaster assistance is coordinated by national bodies, and with the engagement of national actors.

It is also interesting to note pledges made in the year 2018 by international non-state actors to commitments towards implementing the Sendai Framework for Disaster Risk Reduction 2015-2030.9 Examples include the private sector, represented through companies such as SM Prime Holdings, Inc., one of the largest integrated property developers in Southeast Asia, ${ }^{20}$ which pledged to build resilience of Small and Medium Enterprises (smes) in the Philippines, between Jan 2018-Dec 2023. This shall be done through the

18 See more at <http://www.devpolicy.org/why-indonesia-is-right-to-limit-ngos-post -disaster-20181018/>.

19 See more at $<$ https://sendaicommitments.unisdr.org/commitments $>$.

20 See $<$ https://smprime.com/ $>$. 
provision of Information, Education and Communication (IEC), capacity building and data back-up storage facility. ${ }^{21}$ Another example, this time by civil society organisations, is a joint initiative from the international NGO Earthquakes and Megacities Initiative (EMI) ${ }^{22}$ and PLAN International Philippines (PLAN Pils). ${ }^{23} \mathrm{EMI}$ aims to advance urban disaster risk reduction knowledge, policy and practice, functioning as a catalyst for the delivery of scientific and technical knowledge to the end-users, especially through developing capacity in megacities and other complex urban centers of the developing world. PLAN Pils focuses on children's rights including equality for girls. Both together committed to update hazard maps for selected Metro Manila communities, applying the Child-Centered Urban Resilience Framework, that aims to strengthen resilience of local authorities and children against disasters. ${ }^{24}$ This initiative was designed to take place from July 2018 to February 2019.

\footnotetext{
21 See $<$ https://sendaicommitments.unisdr.org/commitments/20190308_003 $>$.

22 See $<$ https://www.preventionweb.net/organizations/713/view $>$.

23 See $<$ https://plan-international.org/philippines $>$.

24 See $<$ https://sendaicommitments.unisdr.org/commitments/20190308_001>.
} 